\title{
Rare late metastasis of testis seminoma to the bladder
}

\author{
Ali Riza Türkoğlu, MD; Soner Coban, MD; Muhammet Guzelsoy, MD; Murat Demirbas, MD; Nazmi Mutlu, MD; \\ Omer Yalcin, $M D$
}

Şevket YIImaz Educational and Research Hospital, Bursa, Turkey

Cite as: Can Urol Assoc J 2015;9(11-12):E823-5. http://dx.doi.org/10.5489/cuai.3250 Published online November 4, 2015.

\section{Abstract}

A 45-year-old male presented to our clinic with complaining of hematuria for a month. The investigations showed a $59 \times 24-\mathrm{mm}$ myxoid mass on the right lateral bladder wall and this was removed with transurethral resection. The histopathology evaluation result was seminoma (classic type). The medical history revealed that the patient had undergone inguinal orchiectomy for a testis tumour 10 years before and the diagnosis was classic type seminoma. He received chemotherapy following the orchiectomy, but had not gone for follow-up after the first year. There was no other metastasis and he was put on the iphosphamide, etoposide, cisplatin (IPE) protocol. The patient has been disease-free for the last 5 months and the tumour markers and cystoscopy were normal. Testis tumours can rarely cause other organ metastases in the late stage even if curative surgery and chemo-radiotherapy were initially administered. Proper follow-up is crucial. It is also necessary to query the tumour history when a tumour in any organ is considered.

\section{Introduction}

Testis tumours are rare, but still the most common malignant tumour in males between the ages of 15 and 35 years. ${ }^{1}$ The great majority of testis neoplasms are germ cell tumours and seminomas make up about $40 \%$ of this group. ${ }^{1}$ The most common site of metastasis is the retroperitoneal region, followed by the mediastinum, the lungs, the brain and solid organs (i.e., liver, kidney, spleen and prostate), and the bones. ${ }^{2,3}$ Testis tumour metastasis to the bladder is very rare. Metastases to the urogenital system are rarely reported, with only a few reported cases with bladder metastasis. ${ }^{4}$ We present a testis tumour case with a very rare bladder metastasis.

\section{Case report}

A 45-year-old male with a 1-month history of hematuria presented to our clinic. His history revealed that he had undergone orchiectomy for a testis tumour (Stage: 1A) 10 years ago. The pathology was classic type testicular seminoma and he received 3 cycles of $\mathrm{BEP}$ (bleomycin, etoposide, cisplatin) postoperatively, but did not attend follow-up 1 year later. Physical examination revealed a right inguinal incision and normal left testis. Serum biochemistry and tumour marker results were within normal limits, with an alpha-fetoprotein (AFP) level of $3.5 \mathrm{ng} / \mathrm{dL}$, beta-human chorionic gonadotropin (B-HCG) level of $1.2 \mathrm{ng} / \mathrm{dL}$, and lactate dehydrogenase (LDH) level of $180 \mathrm{IU} / \mathrm{L}$. Ultrasonography (USG) showed a $60 \times 25-\mathrm{mm}$ polypoid mass on the right lateral bladder wall. Abdominal tomography showed a $59 \times 24-\mathrm{mm}$ polypoid mass extending to the lumen on the right inferolateral bladder wall with no other pathological finding (Fig. 1).

The right lateral bladder wall polypoid mass was resected under general anesthesia. No other bladder tumour was seen. Histopathology evaluation showed pleomorphic tumour cells with a hyperchromatic nucleus and a one-byone arrangement infiltrating the bladder wall. There was widespread necrosis and occasional lymphocytes (Fig. 2).

Immunohistochemical investigations to show tumour infiltration revealed that the atypical cells were pancytokeratin focal (+) (Fig. 3), vimentin (+), SMA (-), myoglobulin (+), S-100 (-), CD34 (-), EMA (-), synaptophysin (-), and chromogranin (-). Morphological and immunohistochemical staining features suggested a malignant tumour infiltrating the bladder, but a definite diagnosis that required a repeat biopsy and an evaluation of the tissue paraffin blocks at the external centre. Immunohistochemical studies at the external center found diffuse and strong SALL4 and OCT3/4 expression leading to a diagnosis of bladder infiltration with classic type seminoma. Repeat transurethral resection was performed 4 weeks later and no tumour was seen on the evaluation of the specimen.

The patient was evaluated again for systemic metastases. F-18 Fluorodeoxyglucose (FDG) positron emission tomog- 


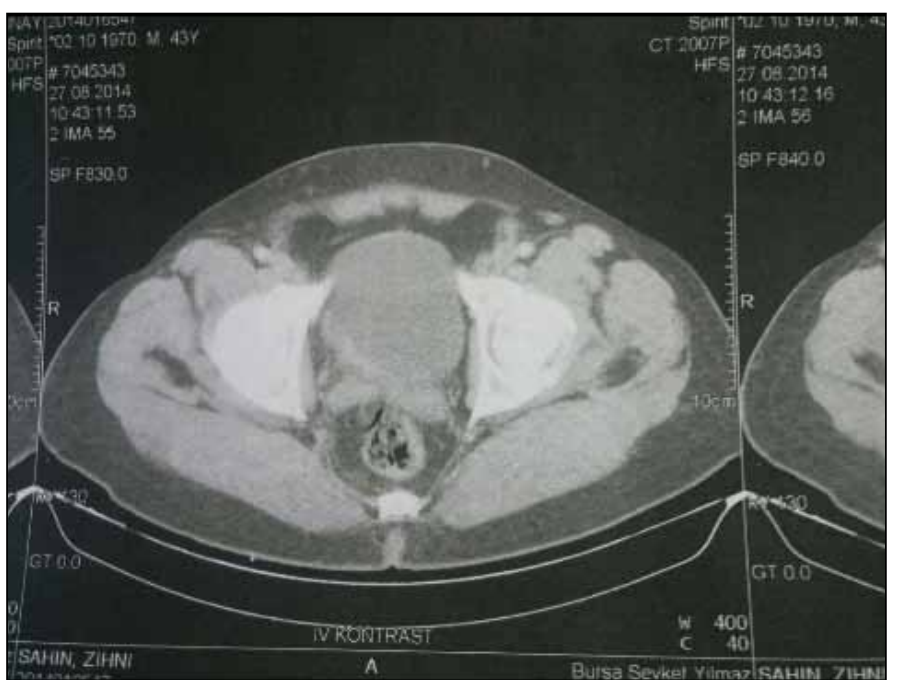

Fig. 1. Tomography appearance, with a mass on the right lateral bladder wall.

raphy (PET) was performed. There was a hypermetabolic FDG area on the right posterior bladder wall, but no other significant FDG involvement in the investigation area as regards metastatic malignancy.

The patient received 4 cycles of chemotherapy (ifosphamide $1200 \mathrm{mg} / \mathrm{m}^{2}$, mesna $1200 \mathrm{mg} / \mathrm{m}^{2}$, etoposide $75 \mathrm{mg} /$ $\mathrm{m}^{2}$, cisplatin $20 \mathrm{mg} / \mathrm{m}^{2}$ ) at 3-week intervals.

The urinalysis, hemogram, biochemistry values and tumour markers were normal on follow-up. Cystoscopy was normal, while PET investigation only showed metabolic regression of the hypermetabolic FDG involvement in the right posterior bladder wall seen at the previous investigation to a physiological level.

\section{Discussion}

Testis tumours are the most common malignant tumours in the 15 to 35 years age group in males and have an increasing full recovery rate thanks to the multimodal treatments being developed. ${ }^{1}$ The localization of the primary tumour, histological subgroups, whether the metastasis includes the lungs, and the AFP, B-HCG and LDH levels are important factors during the diagnosis and follow-up. ${ }^{5}$

Urinary system metastasis is quite rare. Alsolama and colleagues reported on a case with concurrent bladder and testicular seminoma; ${ }^{6}$ Gürbüz and colleagues reported a case with simultaneous bladder carcinosarcoma and testis seminoma. ${ }^{7}$ Another case is present where orchiectomy was performed for testis seminoma and biopsy of the paraaortic and inguinal lymph nodes during a kidney transplant later on in this kidney recipient revealed seminoma again. The patient underwent radiotherapy and received immunosuppressives, but a bladder seminoma was found 3 years later. ${ }^{8}$ Another patient was diagnosed with extragonadal germ cell tumour with lymph node biopsy after retroperitoneal and cervical

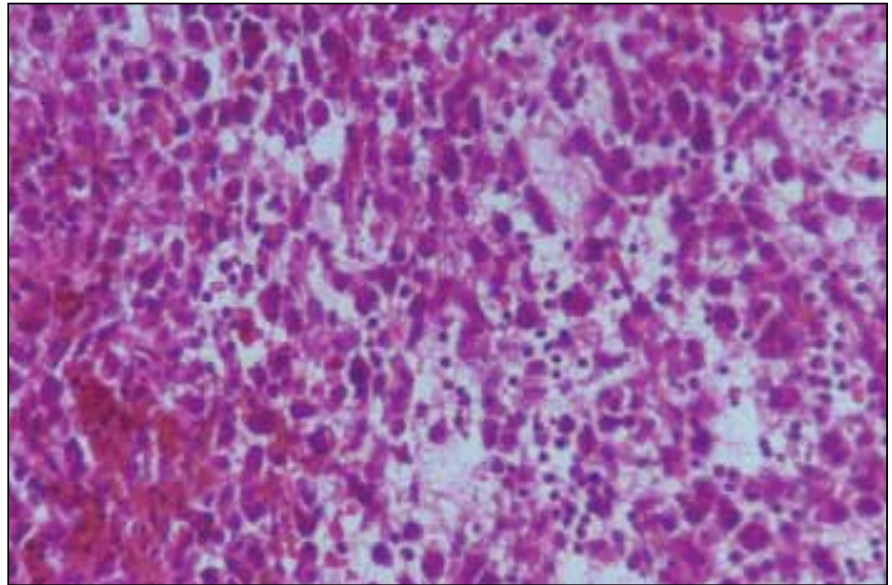

Fig. 2. Pleomorphic tumoral cells with hyperchromatic nucleus. Occasional necrotic cells and lymphocytes are seen (hematoxylin \& eosin $\times 40$ ).

lymphadenopathy was detected. Chemotherapy was administered and the beta-HCG level increased during follow-up. The patient developed hematuria with bladder and right ureter metastasis followed by liver and mesenteric lymph node metastasis leading to his death. ${ }^{9}$ Another article reported a patient who underwent bilateral orchiectomy, retroperitoneal lymph node dissection, and chemotherapy for seminoma; the patient then developed a retrovesical $8 \times 6 \times 5-\mathrm{cm}$ primary seminoma of the prostate 16 years later. ${ }^{10}$ Hashimoto and colleagues reported a primary seminoma involving the prostate. ${ }^{11}$ Khveekar and colleagues reported a case involving the prostate and bladder neck. ${ }^{12}$ Renal, adrenal gland, psoas muscle, gastric, seminal vesicle, bladder, prostate and pericardial involvement are very rare $(<1 \%) .{ }^{4}$ Our literature search did not reveal any other classic type seminoma case that had metastasized only to the bladder 10 years later with no metastasis to the retroperitoneal region or other solid organs.

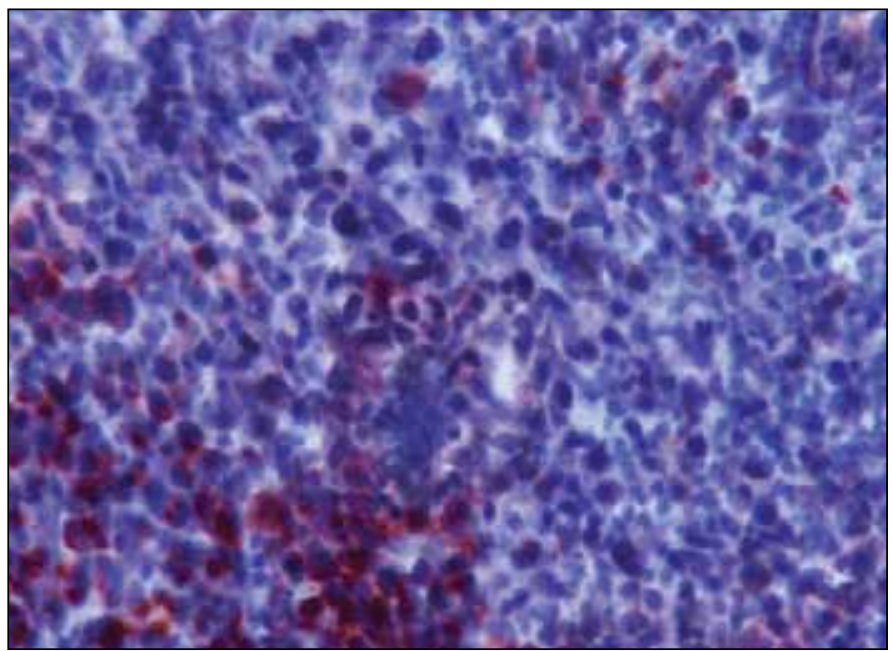

Fig. 3. Tumour cells with positive immunohistochemical staining ( $\mathrm{Pan} \mathrm{CK} \times 40)$. 
Metastases within the first 2 years are considered early for testis tumours, while those after 5 years are considered late. Most metastases develop within the first 2 years. ${ }^{13}$ Followup after radiotherapy and chemotherapy is very important due to the risk of secondary malignancy development. The follow-up frequency varies depending on whether the prognosis is good, moderate or poor, but follow-up every 2 to 4 months for the first 3 years, every 6 months for the 4th to 7 th year, and once a year for life afterwards is necessary. ${ }^{14}$

\section{Conclusion}

Testis tumours should be followed up according to the guidelines. History should be carefully queried and the possibility of solid organ metastasis at the very late stage should always be considered. Treatment should then be planned accordingly.

Competing interests: The authors declare no competing financial or personal interests.

This paper has been peer-reviewed.

\section{References}

1. Richie JP, Steele GS. Neoplasms of the testis. In: Kavaoussi LR, Novick AC, Partin AW and Peters CA eds. Campbell-Walsh Urology. 9th ed. Philadelphia, Saunders, 2007;893-935.
2. McKenney JK, Heerema-McKenney A, Rouse RV. Extragonadal germ cell tumors: A review with emphasis on pathologic features, clinical prognostic variables, and differential diagnostic considerations. Adv Anat Pathol 2007;14:69-92. http://dx.doi.org/10.1097/PaP.0b013e31803240e6

3. Shinagare $A B$, Jagannathan JP, Ramaiya $N$, et al. Adult extragonadal germ cell tumors. AJR Am J Roentgenol 2010;195:W274-80. http://dx.doi.org/10.2214/AJR.09.4103

4. Husband JE, Bellamy EA. Unusual thoracoabdominal sites of metastases in testicular tumors. AJR Am J Roentgenol 1985;145:1165-71. http://dx.doi.org/10.2214/air.145.6.1165

5. Presti JC, Jr. Genital tumors. In: Tanagho EA, McAninch JW; eds. Smith's General Urology. 16th ed. New York; McGraw-Hill, 2004;386-99.

6. Alsolami A, Alotaibi M, Bazarbashi S, et al. Seminoma presenting as a polyploidy bladder mass: A case report. Turk Patoloii Derg 2014:30:69-72.

7. Gürbüz YS, Müezzinoglu B, Cimen K, et al. Synchronous occurrence of bladder carsinoma and testiculer seminoma. Int J Urol 2001;8:404-7. http://dx.doi.org/10.1046/j.1442-2042.2001.00322.x

8. Viddeeleer $\mathrm{AC}$, Lycklama $\mathrm{A}$, Nijeholt $\mathrm{GA}$, et al. A late manifestation of testicular seminoma in the bladder in a renal transplant recipient: A case report. J Urol 1992;148:401-2.

9. Nakatani T, Sugimura K, Naganuma T, et al. Metastatic urinary bladder tumor from extragonadal germ cell tumor: A case report. Oncol Rep 2002:9:1209-11. http://dx.doi.org/10.3892/or.9.6.1209

10. Alsharif $M$, Aslan DL, Jessurun J, et al. Cytologic diagnosis of metastatic seminoma to the prostate and uriner bladder: A case report. Diagn Cytopathol 2008;36:734-8. http://dx.doi.org/10.1002/dc.20881

11. Hashimota T, Ohori M, Sakamoto N, et al. Primary seminoma of the prostate. Int J Urol 2009;16:967-70. http://dx.doi.org/10.1111/j.1442-2042.2009.02403.x

12. Khveerkar JD, Hollanda JM, Rochester $D$, et al. Extragonadal seminoma involving uriner bladder and arising in the prostate. Cancer 1993;71:3972-4. http://dx.doi.org/10.1002/10970142(19930615)71:12<3972::AID-CNCR2820711228>3.0.C0;2-P

13. Lipphardt ME, Albert P. Late relapse of testicular cancer. World J Urol 2004; 22:47-54. http://dx.doi. org/10.1007/s00345-004-0397-9

14. Albers $F$, Albrecht $F$, Algaba $F$, et al. EAU guidelines on testicular cancer: 2011 update. Eur Urol 2011;60:304-19.

Correspondence: Dr. Ali Riza Türkoğlu, Şevket Yılmaz Educational and Research Hospital, Bursa, Turkey; a.turkoglu@hotmail.com 